\title{
Kill and cure: dietary augmentation of immune defences against colon cancer
}

\author{
Fiona Armstrong* and J. C. Mathers \\ Human Nutrition Research Centre, Department of Biological and Nutritional Sciences, University of Newcastle, \\ Newcastle upon Tyne NE1 7RU, UK
}

\begin{abstract}
At its most fundamental, cancer is a genetic disease resulting from inherited or acquired mutations in tumour suppressor genes and proto-oncogenes. Environmental factors, including ingested food components, interact with genetic inheritance to determine individual cancer risk. There is growing evidence that the immune system exerts selective pressure during neoplastic development. Tumour cells that evade this immunosurveillance because they are non-antigenic or because they defend themselves successfully against immune attack have a survival advantage. Effective chemopreventative agents will include dietary components that enhance the immune system's ability to identify transformed cells and to target them for apoptosis.
\end{abstract}

Cancer: Immunosurveillance: Polysaccharides

Cancer arises through genetic alterations in stem cells that result in loss of the normal controls on proliferation, migration and apoptosis. In addition, as solid tumours become established they promote the formation of their own blood vessels to supply $\mathrm{O}_{2}$, nutrients and growth factors, and to remove unwanted products of metabolism. An important feature of tumorigenesis is evasion of the body's systems for immunosurveillance. Each of these key processes (cell proliferation, migration, apoptosis, angiogenesis and immunosurveillance) is a rational target for dietary or pharmaceutical chemopreventative agents. Dietary components that enhance the ability of the immune system to detect and target for apoptosis cells with transformed characteristics are likely to play an important role in cancer prevention.

\section{Epidemiology of colo-rectal cancer}

Colo-rectal cancer (CRC) is the second highest cause of cancer mortality in many Western societies, accounting for 11000 deaths annually in England and Wales, and affecting men and women equally (Department of Health, 1998). Although dominantly-inherited gene mutations are responsible for 10-15\% of CRC cases, the 15-fold range in age-standardized incidence throughout the world, together with the striking changes in incidence which accompany migration from an area of low risk to one of high risk, or vice versa, argue strongly for a major influence by environmental factors, particularly diet. This hypothesis is supported by secular changes, e.g. the fall in CRC incidence in the UK during the 1940s and 1950s attributed to the dietary changes subsequent to food rationing, and the rise in incidence in Japan since 1950 coincident with Westernization of Japanese lifestyles, including diet (Department of Health, 1998). Conventional epidemiology, however, hampered as it is by the lack of reliable data on intakes and composition of foods, is a rather blunt instrument for dissecting out which components of diet are responsible for raising or lowering CRC risk. The recent Committee on Medical Aspects of Health Policy report (Department of Health, 1998) drew the cautious conclusion that there is moderately consistent evidence that diets with less red and processed meat and more vegetables and fibre are associated with reduced risk of colorectal cancer'.

\section{Colo-rectal cancer as a genetic disease}

Inherited or acquired mutations in tumour suppressor genes (resulting in loss of control of cell proliferation) or in oncogenes (resulting in gain of abnormal function by otherwise normal genes) within intestinal stem cells are fundamental to the initiation and development of CRC. There is strong support for the belief that loss of function of both alleles of the tumour suppressor gene adenomatous

Abbreviations: APC, APC, apc, adenomatous polyposis coli; CRC, colo-rectal cancer.

*Corresponding author: Ms Fiona Armstrong, fax +44 (0) 191222 8684, email fiona.armstrong@ncl.ac.uk 
polyposis coli $(A P C)$ is the key event and that $A P C$ may be regarded as the gastrointestinal gatekeeper gene (Reale \& Fearon, 1996). Following inactivation of $A P C$, 'initiated' stem cells have a growth advantage, probably via increased intracellular concentrations of $\beta$-catenin which acts as a nuclear signal in association with the transcription factor Tcf-4 (Behrens et al. 1996) and, over time, acquire mutations in several other key genes including $K-R A S$ and $p 53$. These mutations give the tumour cells greater 'fitness' in a Darwinian sense, allowing them to ignore signals controlling growth, differentiation and migration provided by adjacent cells (Ilyas et al. 1999). An additional selective advantage would be failure to express tumour-specific cell-surface antigens, so making the initiated cells invisible to the immune system (see below). Mutations in one of the six genes encoding the DNA mismatch repair system are responsible for the autosomal dominant condition known as hereditary non-polyposis colon cancer which accounts for about $5 \%$ of CRC cases (Burn et al. 1998). Failure to detect and repair DNA base pair mismatches, introduced by DNA polymerases during replication especially where there are nucleotide repeat sequences, increases the chance of spontaneous mutations occurring in tumour suppressor genes or proto-oncogenes. Dietary components may interact with these genetically-driven processes by altering the extent of DNA damage, augmenting or diminishing the effectiveness of DNA repair or, where repair is inappropriate, targeting of the cell for apoptosis. The recent demonstration in vitro that exposure to aspirin of CRC cell lines with mutations in DNA mismatch repair genes results in suppression of the mutator phenotype and selection of clones of cells with genetic stability (Rüschoff et al. 1998) may be a paradigm for the mechanism of action of salicylate and other dietary constituents in vivo.

\section{Cancer and the immune system}

\section{The concept of immunosurveillance}

Arguments over the existence of immunological surveillance mechanisms that detect and eliminate tumour cells have raged for at least 30 years. Thomas and Burnet (Burnet, 1976) proposed that Darwinian evolution must have evoked such mechanisms for the protection of long-lived higher vertebrates against DNA damage during replication and by exogenous agents. Conversely, Möller \& Möller (1975) argued that there is no immunosurveillance because there is no need (in a Darwinian sense) for it. Since the development of a fully-malignant cell is a very rare event, occurring often only after reproductive age, the counter hypothesis is that there has been no selection pressure to favour the evolution of immunosurveillance (Currie, 1980). Evidence in support of the existence of immunosurveillance includes:

the presence of lymphoid infiltrates in certain tumours which suggests that the immune system 'sees' the tumour;

spontaneous regression of tumours which may be the result of immune action; the greater occurrence of tumours in the neonatal period and in old age when immune function is less efficient (Roitt et al. 1993).

In most forms of immunodeficiency studied to date, however, there is little clinical evidence of increased risk of malignancy, except for tumours of the lymphoid system that may be associated with Epstein-Barr virus infection (Roitt et al. 1993) and Kaposi's sarcoma in patients with acquired immune deficiency syndrome. The observation that some transplantable tumours in mice failed to grow and that these anti-neoplastic mechanisms were absent in T-cell-deficient mice provided experimental evidence that a protective immune response against tumours was possible (Janeway et al. 1999). There is a growing list of candidate tumourrejection antigens which are recognized by cytotoxic $\mathrm{T}$ lymphocytes $\left(\mathrm{CD}^{+}\right.$cells) and which include embryonic antigens and mutated oncogene and tumour suppressor gene products (Janeway et al. 1999). However, there are hints that the immune system may not always be beneficial in defending the body against malignancy. Stewart et al. (1997) reported no effect on the incidence of gastric cancer; colon cancer relative risk was increased (but not significantly), whilst there was a highly significant $(P<0.001)$ reduction in the relative risk for rectal cancer from a survey of 73076 men and women who were chronically immunosuppressed after heart or renal transplantation. In contrast, a well-controlled survey of renal transplant patients in the Nordic countries reported a significant (2-5-fold) excess risk of cancers of the colon, larynx, lung and bladder, and even higher excess risks for some rarer cancers (Birkeland et al. 1995), which suggests that the immune system confers a considerable benefit in combating tumorigenesis.

\section{Some tumours fight back}

It seems probable that many tumours, particularly perhaps in their early stages, evade the immune system because they do not express cell-surface antigens that are recognized as 'non-self'. Other tumours produce cytokines e.g. transforming growth factor- $\beta$ that can inhibit immune responses (Roitt et al. 1993; O'Connell et al. 1999). Activated T-cells express Fas ligand which, when it binds to its receptor Fas, induces apoptosis of the Fas-bearing cell, e.g. a tumour cell. However, some cancer cells counter-attack by expressing Fas ligand on their cell surfaces, which is an apoptotic death signal to which activated T-cells are inherently sensitive (O'Connell et al. 1996; Zeytun et al. 1997). This Fas ligandmediated apoptosis as a means of evasion by tumour cells appears very similar to the mechanisms underlying immune privilege in tissues such as the eye, brain and testis (Griffin \& Ferguson, 1997). Fas ligand-mediated apoptosis may be responsible for the depletion of anti-tumour natural killer cells in the vicinity of tumours as part of the defence against tumour-infiltrating lymphocytes (O'Connell et al. 1999). Another strategy, identified in a large number of lung and colon tumours, is the production of a soluble decoy receptor (DcR3) that binds to Fas ligand and inhibits Fas ligand induced apoptosis (Pitti et al. 1998). 


\section{Modulations of immune responses by dietary factors}

The commonest cause of immune deficiency worldwide is malnutrition (Janeway et al. 1999). The fact that inadequate supply of a very wide range of micronutrients, in addition to protein and lipids, compromises immune function has long been recognized (Ferguson, 1993). More recently, the concept has arisen that varying the intake of specific nutrients, e.g. fatty acids, in adequately-nourished individuals can induce major functional changes in lymphocytes (Calder, 1998) and other elements of the immune system (Grimble, 1998) which may be of clinical significance (Belch \& Muir, 1998). There is some evidence from animal studies of reduced risk of CRC with diets enriched with fish oil (Reddy \& Maruyama, 1986) or certain n-3 fatty acids (Cave, 1991; Oshima et al. 1995) compared with the pro-inflammatory $n-6$ fatty acids. This effect may be due to altered gene expression (Fernandes et al. 1998). Rather less is known about the effects of specific polysaccharides on immune function, although the type and amount of polysaccharide in the diet modulates intestinal cancer risk in rodent models (Young et al. 1996; Zoran et al. 1997; Williamson et al. 1999). Lim et al. (1997) found that the type of NSP included in rat diets could have marked effects on the intestinal immune system, and they reported alterations in circulating concentrations of immunoglobulins and in $\mathrm{CD}^{+}: \mathrm{CD}^{+}$in mesenteric lymph node lymphocytes according to the type of NSP fed.

\section{Dietary polysaccharides and intestinal tumorigenesis in Min mice}

Min mice have a nonsense mutation at codon 850 in the Apc gene which predisposes them to development of adenomas throughout the intestinal tract ( $\mathrm{Su}$ et al. 1992). These mice rarely live longer than 5 months because of the secondary effects of the tumours, including severe chronic anaemia and intestinal blockage (Moser et al. 1990). Min mice have proved to be a useful model for both fundamental studies of $A p c$-driven tumorigenesis (Shoemaker et al. 1997) and of modulation of adenoma formation by pharmaceutical (Jacoby et al. 1996) and dietary agents (Wasan et al. 1997; Vallance et al. 1999).

We are engaged in a series of studies of the influence of dietary polysaccharides on intestinal tumorigenesis and on biomarkers of risk using both Min and Apc1638N mice (Williamson et al. 1999); in the latter, Apc function has been

Table 1. Tumour multiplicity (mean no. of tumours per animal) in Min mice given semi-purified diets containing $100 \mathrm{~g}$ test polysaccharide/kg for 3 months from weaning (CA Higgins, J Coaker, F Armstrong, L Karsai, M Bennett and JC Mathers, unpublished results) (Mean values for twenty animals)

\begin{tabular}{lccccc}
\hline Polysaccharide ... & Cellulose & $\begin{array}{c}\text { Guar } \\
\text { gum }\end{array}$ & $\begin{array}{c}\text { Raw potato } \\
\text { starch }\end{array}$ & $\begin{array}{c}\text { Hylon } \\
\text { VII }\end{array}$ & $\begin{array}{c}\text { Pooled } \\
\text { SEM }\end{array}$ \\
\hline Small intestine & 11.3 & $24 \cdot 0^{*}$ & 14.6 & 17.6 & 3.40 \\
Colon & 0.26 & 0.70 & 0.33 & 0.24 & 0.14 \\
Total & 11.6 & $24 \cdot 7^{*}$ & 14.9 & 17.8 & 3.64 \\
\hline
\end{tabular}

Mean values are significantly different from those for the cellulose-containing diet: ${ }^{*} P<0 \cdot 05$. knocked out by the introduction of a chain-termination mutation at codon 1638 (Fodde et al. 1994). As illustrated in Table 1, tumour multiplicity is readily manipulated by alteration of the nature of the polysaccharide component of the diet fed to Min mice, with more than twice the number of adenomas when the indigestible polysaccharide was guar gum than when it was cellulose. Sources of $\alpha$-amylaseresistant starch gave intermediate results (Table 1). It is not yet known whether these changes in tumour multiplicity are the result of alterations in immune surveillance, but preliminary studies carried out in rats with one of the resistant starch sources suggest that this process may occur. After $34 \mathrm{~d}$ of feeding semi-purified diets differing only in the proportions of Hylon VII and conventional maize starch, lymphocytes isolated from the spleens of animals given $300 \mathrm{~g}$ Hylon VII/kg diet had reduced proliferative responses to mitogenic challenge, whilst those given $100 \mathrm{~g}$ Hylon $\mathrm{VII} / \mathrm{kg}$ diet had an enhanced response (F Armstrong and JC Mathers, unpublished results).

The extent of immune involvement in $A p c$-driven tumorigenesis is poorly understood. Dudley et al. (1996) crossed Min mice with others carrying the severe combined immunodeficiency (scid) mutation (which causes defective double-strand DNA repair and severe immunodeficiency) and examined intestinal tumour multiplicity. The doublymutant Min/scid animals had lower circulating concentrations of total immunoglobulin compared with scid animals and appeared less healthy, as judged by body mass at 3-4 months of age, but there was no detectable effect of the immunodeficiency on small-bowel polyp number (Dudley et al. 1996). The possibility of a novel role for the tumour suppressor gene $A p c$ in modulating gastrointestinal immunity has been proposed by Fox et al. (1997), who observed decreased immune (serum immunoglobulin G), inflammatory and gastric hyperplastic responses to Helicobacter infection in Apc1638 mice compared with wild-type controls. This immune involvement for $A p c$ may arise through its competitive binding to $\beta$-catenin (as an essential element of the wnt/Wingless signalling cascade; Wielenga et al. 1999) and to E-cadherin (Fox et al. 1997). Mice engineered to express a mutant form of cadherin lacking an extracellular domain essential for cell-cell connections had increased bacterial infiltration in their intestinal villi but a blunted mucosal immune response (Hermiston \& Gordon, 1995).

\section{Interactions with intestinal gut bacteria}

The intestinal commensal flora may play an important role in influencing CRC risk through:

(1) production of carcinogens or other agents which damage colonocytes (Kleibeuker et al. 1996);

(2) production of short-chain fatty acids, including butyric acid, which are thought to be anti-carcinogenic (Mclntyre et al. 1993);

(3) modulating the immune response.

Dove et al. (1997) found that Min mice reared in a germfree environment had 2-fold fewer $(P<0.003)$ adenomas in the medial section of the small bowel than conventional 
controls, but tumorigenesis was unaltered in the large bowel where bacterial densities are greatest in conventional mice. The authors offered no convincing explanation for this effect of the murine autochthonous flora, but observed that it was unlikely to be due to alteration of natural killer cell activity. Min mice were crossed with those carrying mutations at the beige (bg) locus and back-crossed with other $b g^{J} / b g^{J}$ mice to produce an N2 population which were heterozygous for Min and homozygous for $b g$. Despite the deficiency in natural killer cell activity due to the homozygous $b g$ mutation (Lane \& Murphy, 1972), there was no significant effect on tumour multiplicity at any intestinal site, and Dove et al. (1997) concluded that the effects 'of diet and microbial status on the Min phenotype deserves further controlled study'.

\section{Anti-neoplastic effects of butyrate}

The apparent protection against CRC afforded by diets rich in 'dietary fibre' (Department of Health, 1998) may be due to the increased production of short-chain fatty acids, and particularly butyrate, with increased flow of fermentable carbohydrate to the large bowel. It is now well established that feeding wheat bran produces substantial increases in large-bowel butyrate concentration in rodent models (Walter et al. 1986; Cheng et al. 1987; McIntyre et al. 1993; Key \& Mathers, 1993; Mathers \& FotsoTagny, 1994), which may be responsible for the reduction in tumorigenesis in carcinogen-treated rats (McIntyre et al. 1993), although this theory is disputed in other studies (Zoran et al. 1997). Direct evidence for the anti-neoplastic effect of butyrate comes from a study in which butyrate was given twice daily by rectal enema to carcinogen-treated rats, resulting in substantial reductions in colonic tumour number and size (D'Argenio et al. 1996).

Exposure of CRC cell lines to physiological concentrations $(1-5 \mathrm{mM})$ of butyrate results in suppression of proliferation, increased differentiation and increased cell death by apoptosis (Hague et al. 1996). When cultured in a medium containing $4 \mathrm{mM}$-butyrate, both Jurkat lymphoid and LIM 1215 colo-rectal cell lines underwent enhanced apoptosis (after a lag period of $14 \mathrm{~h}$ ) which was strictly dependent on new protein synthesis within $10 \mathrm{~h}$ (Medina et al. 1997). This process led to conversion of the proenzyme form of caspase-3 to the catalytically-active effector protease and apoptotic death (Medina et al. 1997). This apoptotic response is associated with the appearance of a specific stable $90 \mathrm{kDa}$ fragment of the APC protein (Browne et al. 1994). Recent studies by Webb et al. (1999) have shown that the $90 \mathrm{kDa}$ fragment of APC produced by butyrate-induced apoptosis consists of an amino terminal sequence containing an intact armadillo repeat domain that is highly conserved across species from Drosophila spp. to human subjects and identical to that produced by the action of recombinant caspase-3. This apoptosis also results in cleavage of $\beta$-catenin, and may be responsible for the dismantling of the cytoskeletal networks which occurs in cells dying by apoptosis (Webb et al. 1999).

The increased differentiation and growth suppression of colon cancer cells produced by butyrate treatment appears to be mediated by histone hyperacetylation caused by inhibition of histone deacetylases (Kruh et al. 1994) via a protein phosphatase of unknown substrate (Cuisset et al. 1998). Treatment of the LS174T colon cancer cell line with 2 mM-butyrate induced dephosphorylation of the nuclear phosphoprotein retinoblastoma protein, transcription of the cyclin D-dependent kinase inhibitor p16, and cell cycle arrest at $\mathrm{G}_{0} / \mathrm{G}_{1}$ (Schwartz et al. 1998). Unphosphorylated retinoblastoma protein binds a number of transcription factors required for $\mathrm{S}$ phase progression, and phosphorylation of retinoblastoma protein in late $G_{0} / G_{1}$ releases a block which allows cells to progress through the cell cycle (Schwartz et al. 1998).

There may be important synergy between butyrate supply from the colon and the immune system which enhances the effectiveness of immunosurveillance. Concurrent treatment with both butyrate and recombinant interleukin 2 suppressed the growth of PROb colon cancer cells injected intraperitoneally into rats (Perrin et al. 1994). PROb cells are only weakly immunogenic, and Perrin et al. (1994) reported that administration of butyrate appeared to increase the immunogenicity of the cancer cells, making them more susceptible to recombinant interleukin 2-activated natural killer cells. There is recent evidence that in vitro several human and rat colon cancer cell lines are sensitized to Fas ligand-mediated apoptosis in the absence of a change in Fas receptor expression on the surface of the target cell (Bonnotte et al. 1998).

\section{Conclusions}

There is growing evidence that the immune system may exert selective pressure during neoplastic development. Transformed cells which evade immunosurveillance, for example because they do not express 'non-self' antigens on their surfaces or because they have effective defence mechanisms against immune attack, will be 'fitter' in a Darwinian sense and have a survival advantage. The mechanism of action of tamoxifen, which is the most clinically-effective chemopreventative agent to date (Fisher et al. 1998), may include increased immunosurveillance through increased natural killer cell densities (Berry et al. 1987). Dietary components that enhance the immune system's ability to identify and target for apoptosis transformed cells will have potential as effective chemopreventative agents.

\section{Acknowledgements}

F.A. holds a Ministry of Agriculture, Fisheries and Food (MAFF) Food Research Studentship. Additional support for these studies is provided by MAFF contract ANO317.

\section{References}

Behrens J, von Kries JP, Kühl M, Bruhn L, Wedlich D, Grosschedll R \& Birchmeier W (1996) Functional interaction of $\beta$-catenin with the transcription factor LEF-1. Nature 382, 638-642.

Belch JJF \& Muir A (1998) $n-3$ and $n-6$ Essential fatty acids in rheumatoid arthritis and other rheumatic conditions. Proceedings of the Nutrition Society 57, 563-569. 
Berry J, Green BJ \& Matheson DS (1987) Modulation of natural killer cell activity by tamoxifen in stage 1 post-menopausal breast cancer. European Journal of Cancer Clinics and Oncology 23, 517-520.

Birkeland SA, Storm SA, Lamm LU, Barlow I, Blohme I, Forsberg B, Eklund B, Fjeldborg O, Friedberg M, Frodin L, Glattre E, Halvorsen S, Holm NV, Jakobsen A, Jorgensen HE, Ladefoged J, Lindholm T, Lundgren G \& Pukkala E (1995) Cancer risk after renal-transplantation in the Nordic countries, 1964-1986. International Journal of Cancer 60, 183-189.

Bonnotte B, Favre N, Reveneau S, Micheau O, Droin N, Garrido C, Fontana A, Chauffert B, Solary E \& Martin F (1998) Cancer cell sensitization to Fas-mediated apoptosis by sodium butyrate. Cell Death and Differentiation 5, 480-487.

Browne SJ, Williams AC, Hague A, Butt AJ \& Paraskeva C (1994) Loss of APC protein expressed by human colonic epithelial cells and the appearance of a specific low-molecular weight form is associated with apoptosis in vitro. International Journal of Cancer 59, 56-64.

Burn J, Chapman PD, Bishop DT \& Mathers J (1998) Diet and cancer prevention: the Concerted Action Polyp Prevention (CAPP) Studies. Proceedings of the Nutrition Society 57, 183-186.

Burnet FM (1976) Immunology, Aging and Cancer. San Francisco, CA: W.H. Freeman and Co.

Calder PC (1998) Dietary fatty acids and lymphocyte functions. Proceedings of the Nutrition Society 57, 487-502.

Cave WT (1991) Dietary n-3 ( $\omega-3)$ polyunsaturated fatty acid effects on animal tumorigenesis. FASEB Journal 5, 2160-2165.

Cheng B-Q, Trimble RP, Illman RJ, Stone BA \& Topping DL (1987) Comparative effects of dietary wheat bran and its morphological components (aleurone and pericarp-seed coat) on volatile fatty acid concentrations in the rat. British Journal of Nutrition 57, 69-86.

Cuisset L, Tichonicky L \& Delpech M (1998) A protein phosphatase is involved in the inhibition of histone deacetylation by sodium butyrate. Biochemical and Biophysical Research Communications 246, 760-764.

Currie G (1980) Cancer and the Immune Response, 2nd ed. London: Edward Arnold.

D'Argenio G, Cosenza V, Cave MD, Iovini P, Valle ND, Lambardi G \& Mazzacca G (1996) Butyrate enemas in experimental colitis and protection against large bowel cancer in a rat model. Gastroenterology 110, 1727-1734.

Department of Health (1998) Nutritional Aspects of the Development of Cancer. Report on Health and Social Subjects no. 48. London: The Stationery Office.

Dove WF, Clipson L, Gould KA, Luongo C, Marshall DJ, Moser AR, Newton MA \& Jacoby RF (1997) Intestinal neoplasia in the $A p c^{M i n}$ mouse: independence from the microbial and natural killer (beige locus) status. Cancer Research 57, 812-814.

Dudley ME, Sundberg JP \& Roopenian DC (1996) Frequency and histological appearance of adenomas in multiple intestinal neoplasia mice are unaffected by severe combined immunodeficiency (scid) mutation. International Journal of Cancer $\mathbf{6 5}$, 249-253.

Ferguson A (1993) Nutrition and the immune system. In Human Nutrition and Dietetics, 9th ed. pp. 685-700 [JS Garrow and WPT James, editors]. Edinburgh: Churchill Livingstone.

Fernandes G, Troyer DA \& Jolly CA (1998) The effects of dietary lipids on gene expression and apoptosis. Proceedings of the Nutrition Society 57, 543-550.

Fisher B, Constantino JP, Wickerman L, Redmond CK, Kavanah M, Cronin WM, Vogel V, Robidoux A, Dimitrou N, Atkins J, Daly M, Weinands S, Tan Chui E, Ford L \& Wolmark N (1998) Tamoxifen for prevention of breast cancer: report of the National
Surgical Adjuvant Breast and Bowel Project P-1 Study. Journal of the National Cancer Institute 90, 1371-1388.

Fodde R, Edelman W, Yang K, van Leeuwan C, Carlson C, Renault B, Breukel C, Alt E, Lipkin M, Khan PM \& Kucherlapati R (1994) A targeted chain-termination mutation in the mouse Apc gene results in multiple intestinal tumors. Proceedings of the National Academy of Sciences USA 91, 8969-8973.

Fox JG, Dangler CA, Whary MT, Edelman W, Kucherlapati R \& Wang TC (1997) Mice carrying a truncated Apc gene have diminished gastric epithelial proliferation, gastric inflammation and humoral immunity in response to Helicobacter felis infection. Cancer Research 57, 3972-3978.

Griffin TS \& Ferguson TA (1997) The role of FasL-induced apoptosis in immune privilege. Immunology Today 18, 240-244.

Grimble RF (1998) Dietary lipids and the inflammatory response. Proceedings of the Nutrition Society 57, 535-542.

Hague A, Butt AJ \& Paraskeva C (1996) The role of butyrate in intestinal colonic epithelial cells: an energy source or inducer of differentiation and apoptosis? Proceedings of the Nutrition Society 55, 937-943.

Hermiston ML \& Gordon JI (1995) Inflammatory bowel disease and adenomas in mice expressing a dominant negative $N$-cadherin. Science 270, 1203-1207.

Ilyas M, Straub J, Tomlinson IPM \& Bodmer WF (1999) Genetic pathways in colorectal and other cancers. European Journal of Cancer 35, 335-351.

Jacoby RF, Marshall DJ, Newton MA, Novakovic K, Tutsch K, Cole C, Lubet RA, Kelloff GJ, Verma A, Moser AR \& Dove WF (1996) Chemoprevention of spontaneous intestinal adenomas in the $A p c^{\mathrm{Min}}$ mouse model by the nonsteroidal anti-inflammatory drug piroxicam. Cancer Research 55, 4479-4485.

Janeway CA Jr, Travers P, Walport M \& Capra JD (1999) Immunobiology. The Immune System in Health and Disease, 4th ed. London: Current Biology Publications.

Key FB \& Mathers JC (1993) Gastrointestinal responses of rats fed on white and wholemeal breads: complex carbohydrate digestibility and the influence of dietary fat content. British Journal of Nutrition 69, 481-495.

Kleibeuker JH, Nagengast FM \& van der Meer R (1996) Carcinogenesis in the colon. In Prevention and Early Detection of Colorectal Cancer, pp. 45-62 [GP Young, P Rozen and B Levin, editors]. London: WB Saunders Co. Ltd.

Kruh J, Tichonicky L \& Defer N (1994) Effect of butyrate on gene expression. In Short Chain Fatty Acids, pp. 135-147 [HJ Binder, $\mathrm{JH}$ Cummings and $\mathrm{K}$ Soergel, editors]. Lancaster: Kluwer Academic Publications.

Lane PW \& Murphy ED (1972) Susceptibility to spontaneous pneumonitis in an inbred strain of beige and satin mice. Genetics 72, 451-460.

Lim BO, Yamada K, Nonaka M, Kuramoto Y, Hung P \& Sugano M (1997) Dietary fibre modulates indices of intestinal immune function in rats Journal of Nutrition 127, 663-667.

McIntyre A, Gibson PR \& Young GP (1993) Butyrate production from dietary fibre and protection against large bowel cancer in a rat model. Gut 34, 386-391.

Mathers JC \& FotsoTagny J-M (1994) Diurnal changes in largebowel metabolism: short-chain fatty acids and transit time in rats fed on wheat bran. British Journal of Nutrition 71, 209-222.

Medina V, Edmonds B, Young GP, James R, Appleton S \& Zalewski PD (1997) Induction of caspase-3 protease activity and apoptosis by butyrate and trichostatin A (inhibitors of histone deacetylase): Dependence on protein synthesis and synergy with a mitochondrial/cytochrome $c$-dependent pathway. Cancer Research 57, 3697-3707.

Möller G \& Möller E (1975) Considerations of some current concepts in cancer research. Journal of the National Cancer Institute 55, 755-759. 
Moser AR, Pitot HC \& Dove WF (1990) A dominant mutation that predisposes to multiple intestinal neoplasia in the mouse. Science 247, 322-324.

O'Connell J, Bennett MW, O'Sullivan GC, Collins JK \& Shanahan F (1999) Fas counter-attack - the best form of defense? Nature Medicine 5, 267-268.

O'Connell J, O'Sullivan GC, Collins JK \& Shanahan F (1996) The Fas counterattack: Fas-mediated T cell killing by colon cancer cells expressing Fas ligand. Journal of Experimental Medicine 184, 1075-1082.

Oshima M, Takahashi M, Oshima H, Tsutsumi M, Yazawa K, Sugimura T, Nishimura S, Wakabayashi K \& Taketo MM (1995) Effects of docosahexaenoic acid (DHA) on intestinal polyp development in Apc ${ }^{\Delta 716}$ knockout mice. Carcinogenesis 16, 2605-2607.

Perrin P, Cassagnau E, Burg C, Patry Y, Vavasseur F, Harb J, Le Pendu J, Douillard J-Y, Galmiche J-P, Bornet F \& Meflah K (1994) An interleukin 2/sodium butyrate combination as immunotherapy for rat colon cancer peritoneal carcinomatosis. Gastroenterology 107, 1397-1708.

Pitti RM, Marsters SA, Lawrence DA, Roy M, Kischkel FC, Dowd P, Huang A, Donahue CJ, Sherwood SW, Baldwin DT, Godowski PJ, Wood WI, Gurney AL, Hillan KJ, Cohen RL, Goddard AD, Botstein D \& Ashkenazi A (1998) Genomic amplification of a decoy receptor for Fas ligand in lung and colon cancer. Nature 396, 699-703.

Reale MA \& Fearon ER (1996) Gene defects in colorectal carcinogenesis. In Prevention and Early Detection of Colorectal Cancer, pp. 63-86 [GP Young, P Rozen and B Levin, editors]. London: WB Saunders Co. Ltd.

Reddy BS \& Maruyama H (1986) Effect of dietary fish oil on azoxymethane-induced colon carcinogenesis in male F344 rats. Cancer Research 46, 3367-3370.

Roitt IM, Brostoff J \& Male DK (1993) Immunology, 3rd ed, London: Mosby.

Rüschoff J, Wallinger S, Dietmaier W, Bocker T, Brockhoff G, Hofstädter F \& Fishel R (1998) Aspirin suppresses the mutator phenotype associated with hereditary nonpolyposis colorectal cancer by genetic selection. Proceedings of the National Academy of Sciences USA 95, 11301-11306.

Schwartz B, Avivi-Green C \& Polak-Charcon S (1998) Sodium butyrate induces retinoblastoma protein phosphorylation, p16 expression and growth arrest of colon cancer cells. Molecular and Cellular Biochemistry 188, 21-30.

Shoemaker AR, Gould KA, Luongo C, Moser AR \& Dove WF (1997) Studies of neoplasia in the Min mouse. Biochemica et Biophysica Acta 1332, F25-F48.
Stewart T, Henderson R, Grayson H \& Opelz G (1997) Reduced incidence of rectal cancer, compared to gastric and colonic cancer, in a population of 73,076 men and women chronically immunosuppressed. Clinical Cancer Research 3, 51-55.

Su LK, Kinzler KW, Vogelstein B, Preisinger AC, Moser AR, Luongo C, Gould KA \& Dove WF (1992) Multiple intestinal neoplasia caused by a mutation in the murine homologue of the APC gene. Science 256, 668-670.

Vallance C, Coaker J \& Mathers JC (1999) Guar gum increases but cholesterol suppresses intestinal tumorigenesis in the Min mouse. Proceedings of the Nutrition Society 58, 72A.

Walter DJ, Eastwood MA, Brydon WG \& Elton RA (1986) An experimental design to study colonic fibre fermentation in the rat: the duration of feeding. British Journal of Nutrition 55, 456-479.

Wasan HS, Novelli M, Bee J \& Bodmer WF (1997) Dietary fat influences polyp phenotype in multiple intestinal neoplasia mice. Proceedings of the National Academy of Sciences USA 94, $3308-3313$.

Webb SJ, Nicholson D, Bubb VJ \& Wyllie AH (1999) Caspasemediated cleavage of APC results in an amino terminal fragment with an intact armadillo repeat domain. FASEB Journal 13, 339-346.

Wielenga VJM, Smits R, Korinek V, Smit L, Kielman M, Fodde R, Clevers H \& Pals ST (1999) Expression of CD44 in Apc and Tcf mutant mice implies regulation by the WNT pathway. American Journal of Pathology 154, 515-523.

Williamson SLH, Kartheuser A, Coaker J, Dehghan Kooshkghazi M, Fodde R, Burn J \& Mathers JC (1999) Intestinal tumorigenesis in the $A p c 1638 \mathrm{~N}$ mouse treated with aspirin and resistant starch for up to 5 months. Carcinogenesis 20, 805-810.

Young GP, McIntyre A, Albert V, Folino M, Muir JG \& Gibson PR (1996) Wheat bran suppresses potato starch-potentiated colorectal tumorigenesis at the aberrant crypt stage in a rat model. Gastroenterology 110, 508-514.

Zeytun A, Hassuneh M, Nagarkatti M \& Nagaratti PS (1997) FasFas ligand-based interactions between tumor cells and tumorspecific cytotoxic T lymphocytes: A lethal two-way street. Blood 90, 1952-1959.

Zoran DL, Turner ND, Taddeo SS, Chapkin RS \& Lupton JR (1997) Wheat bran reduces tumor incidence in a rat model of colon cancer independent of effects on distal luminal butyrate concentrations. Journal of Nutrition 127, 2217-2225. 